Paidéia, 2003, 12(24), 229-240

\title{
GRAVIDEZ NA ADOLESCÊNCIA E MUDANÇA DO PAPEL SOCIAL DA MULHER'
}

\author{
Isete Stibbe Neiverth ${ }^{2}$ \\ Gustavo Biasoli Alves \\ Universidade Estadual do Oeste do Paraná
}

\begin{abstract}
RESUMO: A pesquisa discute como as mudanças sociais que vêm ocorrendo no papel social da mulher estão se refletindo na questão da gravidez não programada na adolescência. $O$ principal objetivo foi verificar a existência de relações entre a gravidez na adolescência e a mudança no papel social da mulher. A população foi formada por adolescentes (13-18 anos), residentes no Bairro Santa Terezinha, Palotina - Paraná, tendo em comum o fato de haverem engravidado pelo menos uma vez quando solteiras, nos anos de 2000-2001. Concluise que apesar das mudanças que ocorreram no papel social das mulheres permaneceram resquícios de uma cultura masculina muito forte. Essa cultura masculina que antes relacionava virgindade com inocência, nos dias atuais relaciona inocência com a entrega amorosa de uma mulher que, no calor da paixão, não consegue resisitir aos avanços e carícias de seu parceiro Também constatou-se que mudanças no papel social desempenhado pelas mulheres são históricas e por isso alteram-se conforme a época e o lugar, bem como, podem conviver num mesmo contexto social concepções diferentes sobre determinado papel social.
\end{abstract}

Palavras-Chave: papel social, adolescência, gravidez

\section{ADOLESCENCE PREGNANCY AND SOCIAL ROLE CHANGES}

\begin{abstract}
This article discusses how social changes that are happening on women social role are been reflected in adolescence pregnancy. The main target was to verify the existence of relations between then. The sample was formed by adolescents (13 to18 years old) that live in Palotina, state of Parana - Brazil and had in common at least one pregnancy while singles in 2000-2001. Conclusion is that nevertheless the chances that have happened on women social role there some remains of very strong male culture. This male culture made a relation betwenn virginity and innocence in the past. Nowadays it has changed to innocence equals not to resist to the partner's touch and attacks. A woman burning in desire must not do that. So social changes that had happened in women's social role are historic e because of that change from one place or time to another also different conceptions about a given social role may live together.
\end{abstract}

Key-word: social role, adolescence, pregnancy

O fenômeno social da gravidez na adolescência, relacionado com as mudanças que ocorreram no papel das mulheres, insere-se dentro da produção científica sobre as temáticas gênero e mulher.

A abordagem sociológica da noção de gênero aponta para o caráter relacional do feminino $\mathrm{e}$ do masculino. Isto significa dizer que o modo de agir e pensar dos homens e mulheres não são determinados pela anatomia física que diferencia os sexos, mas são condutas sociais. Como os papéis masculinos e

\footnotetext{
${ }^{1}$ Artigo recebido para publicação em 08/2002; aceito em 12/2002 2 Endereço para correspondência: Isete Stibbe Neiverth, Universidade Estadual do Oeste do Paraná, Rua da Faculdade, 645, Jardim La Salle, Toledo, PR, Cep 85903-320, E-mail ilario@vn.com.br
}

femininos são definidos pela cultura, eles mudam de um contexto social para outro e sofrem alterações com o passar dos anos.

A urbanização, a industrialização e os avanços tecnológicos têm contribuído para que ocorram mudanças nos papéis sociais desempenhados pelas mulheres, atingindom concepções como virgindade, namoro e casamento alterando a maneira como os homens e as mulheres se relacionam.

Os movimentos feministas e a descoberta de métodos anticoncepcionais favoreceram o engajamento

de muitas mulheres na luta por igualdade de direitos 
com os homens e sua inserção no mercado de trabalho; trabalhando fora, o seu relacionamento com os filhos, casa e marido é modificado, tendo como consequência alterações na organização familiar. Também acontece de a mulher passar a dedicar mais tempo aos estudos, em função das exigências do mercado. E, com a possibilidade dos métodos anticoncepcionais o planejamento familiar torna-se uma realidade. Enfim, observam-se mudanças de valores com relação aos papéis de esposa, mãe, profissional e de estudante.

O que se pergunta, diante desta situação que não mais atribui um alto valor à preservação da virgindade, sinônimo de inocência para que a mulher se torne apta ao casamento, é o "Porque ocorre a gravidez na adolescência?", uma vez que a adolescente conhece e possui acesso aos meios anticoncepcionais à disposição em postos de saúde e farmácias. Se ela tem a liberdade de controlar sua fecundidade através do uso de anticoncepcionais e de escolher os parceiros com quem terá relações amorosas, o que pode estar fazendo com que ela não utilize os métodos adequados para evitar uma gravidez?

Para responder ao problema em questão, deve-se ter em mente a complexa relação que existe entre indivíduo e estrutura social. Enquanto há por parte da sociedade pressão para que a adolescente perca a virgindade, por outro, ela possuir vários parceiros será considerada imoral, e olhada com desprezo.

A partir dessas reflexões tem-se como hipótese inicial que existe relação entre o índice de gravidez não programada nas adolescentes e a mudança do papel social da mulher, definindo-se como objetivos de pesquisa:

1 - Descrever a relação entre o índice de gravidez não programada das adolescentes e a mudança do papel social da mulher na sociedade;

2- Analisar como a mudança do papel social da mulher pode influenciar no índice de gravidez na adolescência;

3- Buscar identificar se, conforme Desser (1993), socialmente é desejável que a entrega amorosa da adolescente não tenha um caráter premeditado em que: a) o uso da racionalidade na liberdade sexual para evitar uma gravidez através da contracepção seria tomado como evidência de promiscuidade; e b) arriscar-se à gravidez seria uma defesa de sua inocência.

Mas, para poder discutir essas questões, é necessário que, antes da pesquisa empírica, alguns temas sejam vistos de acordo com o que traz a literatura.

\section{Mudanças no papel social da mulher brasileira}

As relaçōes de gênero mudam de acordo com a época e o lugar, em função de um conjunto de fatores.

A análise da história da mulher permite mostrar como o seu papel social sofreu alterações; a urbanização e a industrialização afetaram grandemente as instituições familiares, fazendo com que ocorressem mudanças em concepções como namoro, casamento, maternidade e virgindade, fazendo com que se modicassem os papéis sexual, de mãe, de esposa, o profissional e o de estudante das mulheres; essas constatações levam a que se pergunte qual a relação dessas mudanças com a gravidez na adolescência.

É certo que industrialização causou profundas alterações no modo de vida brasileiro que, até o inicio do século XIX, era mais caracteristicamente rural, sendo a família considerada dentro do modelo patriarcal, com um comando exercido pelo pai, que tinha poder sobre seus dependentes, agregados e escravos, habitava a casa grande e dominava a senzala.

Por outro lado, o início do século XX é um período de transição das relações sociais senhoriais para as do tipo burguês que se fizeram acompanhar de uma crescente urbanização e de mudanças na maneira de as famílias se organizarem.

O crescimento e proliferação das cidades modifica o estilo de construção das residências, o que, por sua vez, leva à introdução das noções de público e privado, antes inexistentes, porque as casas não tinham uma clara delimitação dos cômodos, o que facilitava uma convivência entre escravos, criados, agregados e familiares de forma mais aberta. Externamente, também, as moradias eram construídas umas ao lado das outras, sem afastamento após a calçada. Depois da libertação dos escravos e proclamação da república, aumentam as construções isoladas, as quais internamente começam a apresentar separação dos 
recintos, o que vai possibilitar o aparecimento da privacidade entre os membros da família.

Também é dessa época o valor atribuído às ideáis de que a mãe deveria cuidar da educação dos filhos e não deixá-los interiamente aos cuidados de amas ou estranhos, bem como, ser atenciosa e boa esposa para o seu marido. Embora a autoridade familiar se mantivesse em mãos masculinas, os homens dependiam da imagem que suas mulheres traduziam para o restante de seu grupo de convívio, significando um capital simbólico importante. O sucesso da família, então, também passou a depender da mulher.

Nesta época, segundo Rodrigues (1992) o sentimento amoroso começa a se institucionalizar e a ser reconhecido como base para o matrimônio, em substituição ao casamento arranjado pelas famílias; isto, por sua vez, altera o namoro. No século XVIII os pais tinham por norma vigiar constantemente as moças, o que não impedia os enamorados de encontrarem um jeito para demonstrar que gostavam um do outro: a moça, a princípio, mostrava que se interessava pelo rapaz quando correspondia aos seus olhares. Já no segundo encontro, o rapaz dava um jeito de chegar perto dela e, às escondidas, pois os encontros aconteciam por ocasião das missas quando as famílias (D'Incao, 1997) iam para as cerimônias, e não era possível conversarem, ele se aproximava e dava-lhe um rápido e forte beliscão. Já, no século XIX, ocorre um afrouxamento da vigilância paterna, o que não deve ser entendido como libertação feminina, pois, ele só acontece porque as próprias mulheres passaram a se autovigiar.

A passagem da vigilância dos pais para a das moças deu-se juntamente com a mudança do casamento arranjado para o determinado pelo afeto; como este envolvia os sentimentos, elas precisavam da oportunidade de conhecer melhor seus pretendentes; e para que pudessem ficar a sós com eles, deveriam controlar seus impulsos sexuais.

Na década de 20 do século passado, a virgindade possuía um real valor para os pais, tendo, além das atribuições morais, implicações práticas, pois podia ser barganhada para conseguir um bom casamento, que beneficiasse toda a família da noiva. "A virgindade era um 'cristal' que não devia ser quebrado à toa" (Fonseca, 1997, p. 529).
Este, no entanto, era o padrão de comportamento esperado para as jovens de famílias burguesas ou de classe média, pois a mulher pobre sempre teve um papel diferente, sendo as famílias das camadas populares vistas como desorganizadas pelo fato de não corresponderem ao modelo normal ditado pela burguesia, revelando a existência de diversidade nas dinâmicas familiares no Brasil.

A tradição de que o homem deve ser o chefe da casa e a mulher a rainha do lar, dedicando-se exclusivamente aos cuidados do marido e filhos, estava presente na moral oficial, mas não era vivenciada desta forma pela maioria das mulheres pobres, que, muitas vezes, além dos trabalhos domésticos, eram as principais responsáveis pelo sustento da família.

Conforme Fonseca (1997), os censos do século XX revelam que em certas cidades até $40 \%$ das mulheres eram chefes-de-família. $E$ este fato, no período é explicado, de certo modo, observando o cotidiano dos homens que mudavam constantemente de localidade devido à instabilidade dos empregos, abandonando suas companheiras e filhos que podiam ficar vários anos sem notícias, ou ainda as deixavam alegando que eram relaxadas e possuíam mau gênio; elas, sozinhas, ficavam numa situação difícil encontrando-se em meio a "dois fogos: por um lado, pressões econômicas e políticas que impunham a necessidade de um (novo) marido; por outro, a condenação pela opinião pública de qualquer mulher que tivesse mais de um homem na vida" (Fonseca, 1997, p. 525). E isto tinha por base a rivalidade masculina, pois a honra de um homem estava ligada, em grande parte, ao controle que exercia sobre a sexualidade feminina, sendo humilhante perder a mulher para outro, mesmo tendo abandonado o lar.

Apesar da realidade não deixar espaço para seguir a moral oficial, a mulher pobre era condenada pela lei oficial, mas, ao mesmo tempo, dentro de seu contexto social, alguns deslizes eram permitidos, resultantes do que vivenviavam, o que reforça a existência de padrões alternativos.

\section{Visão Social do Papel Profissional Feminino nos anos 1890 a 1930}

Tendo em mente que com o início da industrialização brasileira começa-se a atribuir às mulhe- 
res um papel profissional, antes somente privilégio dos homens considerados os chefes e provedores da família, pode-se verificar que o trabalho feminino alterou o papel de mãe, esposa e mesmo o sexual.

Retornando a um passado nem tão longínquo, tem-se relatos das dificuldades enfrentadas pelas mulheres para ingressarem no mercado de trabalho. Além dos preconceitos sociais, os primeiros obstáculos começavam no interior da própria família, com os pais afirmando que as filhas deveriam seguir o papel de esposas e mães, sendo o casamento considerado uma garantia para o futuro. Rago (1997) afirma que, apesar da modernização, as relações familiares continuavam a se pautar por um forte moralismo, tanto nas camadas ricas quanto nas mais pobres.

"Nesse contexto, com a crescente incorporação das mulheres ao mercado de trabalho e à esfera pública em geral, o trabalho feminino fora do lar passou a ser amplamente discutido, ao lado de temas relacionados à sexualidade: adultério, virgindade, casamento e prostituição. Enquanto o mundo do trabalho era representado pela metáfora do cabaré, o lar era valorizado como o ninho sagrado que abrigava a "rainha do lar" e o "reizinho da família". Diante do crescimento urbano vertiginoso de muitas cidades brasileiras, com um grande contingente de trabalhadores concentrados nos bairros operários, o mundo público acabou sendo considerado um espaço ameaçador para a moralidade das mulheres $e$ crianças. Evidentemente, os problemas decorrentes da urbanização - o aumento das epidemias, da violência, dos roubos a presença de mendigos, loucos, cáftens; menores abandonados nas ruas da cidade, sem falar das agitações políticas, em grande parte promovidas por anarquistas e socialistas - aumentavam a insegurança..." (Rago, 1997, p. 588)

Para a autora, as mulheres das camadas médias que iniciavam suas carreiras como médicas, advogadas, biólogas, pintoras e pianistas sofriam com o moralismo dominante que afirmava ser o trabalho fora do lar caminho para a desagregação da família, pois elas, ao trabalharem durante todo o dia não teriam tempo para cuidar do marido, casa e filhos.

Contudo, apesar de vários setores da sociedade tentarem impedir as mudanças, elas vão acontecendo lentamente, junto com a permanência de valores muito arraigados. Mesmo as profissões femininas sendo consideradas uma ameaça para as relações familiares, fica cada vez mais frequente o exercício de uma profissão pelas mulheres. Isto, sem sombra de dúvida, aponta para o fato de que a despeito das conquistas, o papel social feminino ainda estava firmemente vinculado ao lar: O pai que não tem tempo para se dedicar aos filhos e é desculpado, mas a mãe não. Com relação à vida profissional, construiu-se uma concepção de que o trabalho fora de casa seria uma ocupação transitória que deveria ser abandonada sempre que se impusesse a verdadeira missão da mulher de esposa e mãe.

A incompatibilidade entre casamento/maternidade com a vida profíssional feminina é pois uma construção social que representa a valorização de sua função no lar, através de vínculos entre o espaço doméstico e a sociedade.

\section{Mulheres nos anos 50 e 60 em diante}

Neste período serão observadas mudanças significativas na sociedade e no papel das mulheres. Segundo Bassanezi (1997):

"O Brasil dos anos 50 viveu um periodo de ascensão da classe média. Com o fim da Segunda Guerra Mundial, o país assistiu otimista e esperançoso ao crescimento urbano e à industrialização sem precedentes que conduziram ao aumento das possibilidades educacionais e profissionais para homens e mulheres. Democracia e participação eram idéias fortalecidas nos discursos políticos. Em geral, ampliaram-se aos brasileiros as possibilidades de acesso à informação, lazer e consumo. As condições de vida nas cidades diminuíram muitas das distâncias entre homens e mulheres; práticas sociais do namoro à intimidade familiar também sofreram modificações." ( $p$. 608) 
Conforme a autora, as distinções entre os papéis femininos e masculinos continuavam claras, permanecendo forte a existência de uma moral sexual diferenciada e, apesar de ser cada vez mais comum o trabalho remunerado da mulher ele era visto como subsidiário ao do homem, considerado o chefe da casa.

Com relação ao namoro, casamento e virgindade nos anos 50, as jovens eram classificadas em moças de família (Bassanezi, 1997) ${ }^{4}$ e moças levianas.

Nesse tempo, já estava fora de moda contrair matrimônio apenas pela vontade dos pais, sem afeto. Para casar as moças tinham que conhecer rapazes, fazendo com que a preocupação da sociedade recaísse na educação voltada para o seu autocontrole, o que servia como espécie de guia que mostrava como elas deveriam se comportar para serem consideradas de família e não levianas, evitando-se a companhia destas últimas, sob pena de não conseguirem casamento, ou seja, as amizades eram extremamente seletivas.

Também, conforme a educação para o autocontrole, não era recomendável para a reputação de uma jovem usar roupas muito ousadas e sensuais, sair com vários rapazes, ser vista em lugares escuros ou em situação que sugerisse intimidades com um homem, sendo prejudicial para seus planos de casamento ter fama de leviana, namoradeira, vassourinha ou maçaneta (que passa de mão em mão), enfim, de garota fácil, pois poucos homens aceitavam a idéia de contraírem matrimônio com uma moça deflorada por outro, ou seja, a virgindade continuava representando uma necessidade, pois indicava a pureza das mulheres.

A escolha dos futuros cônjuges era feita pelos rapazes e moças, porém a influência dos pais, ainda que menor do que nos tempos do casamento arranjado, continuava forte e considerada socialmente como um cuidado deles para com o futuro de seus filhos. Nem sempre as expectativas das filhas

\footnotetext{
4 "As moças de família eram as que se portavam corretamente, de modo a não ficarem mal faladas. Tinham gestos contidos, respeitavam os pais, preparavam-se adequadamente para o casamento, conservavam sua inocência sexual e não se deixavam levar por intimidades físicas com os rapazes. Eram aconselhadas a se comportarem de acordo com os princípios morais aceitos pela sociedade, mantendo-se virgens até o matrimônio enquanto aos rapazes era permitido terem experiências sexuais."
}

correspondiam às do pai, mas ambos tinham como critério principal de avaliação que um bom partido era honesto, trabalhador e precisava ter condições de sustentar uma família.

Tornou-se comum falar que o casamento só deveria se realizar quando houvesse amor, que o namoro ideal não duraria muito e nem seria muito curto, precipitando decisões sérias e definitivas. Mas, um noivado longo prejudicava a moça, que se tornava alvo de fofocas e levantava suspeitas sobre as verdadeiras intenções do rapaz; portanto, as decisões eram influenciadas pela cobrança, por parte da sociedade, de que o namoro terminasse em casamento.

Os padrões de comportamente precedentes passaram por profundas alterações entre os anos 60 a 90. Com o feminismo, que se estrutura como movimento social, a partir da segunda metade da década de setenta, a pauta de discussão inclui as várias modalidades de interação afetivo-sexuais, os estereótipos de gênero existentes na sociedade.

As feministas contribuíram, assim, para que ocorressem mudanças no papel social desempenhado pela mulher ao afirmarem que a sexualidade e a reprodução eram um direito dela, defendendo a liberdade e autonomia de escolha do número de parceiros e filhos.

A educação também passou por transformações; conforme Rosemberg (1994), nas décadas de 70 à 90 pode ser observado um aumento na proporção das mulheres que participam do sistema educacional, principalmente no ensino de $2^{\circ}$ e $3^{\circ}$ Graus. Segundo a autora, em 1989, dentre os 36,6 milhões de estudantes tendo 5 anos ou mais de escolaridade, $51,4 \%$ são mulheres, revelando uma porcentagem ligeiramente superior à dos homens. Isto trouxe reflexos na quantidade e qualidade de sua inserção no mercado de trabalho, fazendo com que elas, que representavam cerca de um quinto da mão-de-obra nacional empregada em 1970, superassem um terço do total de trabalhadores, em 1990.

De acordo com Saffioti (1994), o fato de as mulheres geralmente apresentarem um nível de escolaridade mais alto do que o dos homens não significa que deixaram de sofrer descriminações no ambiente de trabalho; pelo contrário, mesmo exercendo funções iguais elas continuaram recebendo salários menores, porém, é verdade que têm sido menos ex- 
postas ao desemprego.

Devido à introdução da mulher no mundo profissional, surje um novo padrão de família, bastando dois ou apenas um filho para tornar o casal realizado, e embora o papel de mãe continue sendo muito valorizado, a família pequena é vista socialmente como ideal.

Assim, as mudanças dos anos 60 a 90 , na escolarização e profissionalização das mulheres, trouxeram reflexos na organização familiar, no papel de mãe, reduzindo consequentemente o tamanho das famílias. Essas mudanças também atingiram as concepções de virgindade e namoro, que, por sua vez, estão ligadas ao comportamento sexual das adolescentes, determinando o índice de gravidez não programada na adolescência.

Dados de diferentes trabalhos mostram que a gravidez na adolescência é um tema que preocupa a sociedade brasileira como um todo, sendo um fenômeno que ultrapassa as fronteiras do país, recebendo atenção da Organização Mundial de Saúde. O Brasil tem uma média de $25,8 \%$ e no Estado do Paraná ela é de 22,8\% (Da AENotícias, 2000) sendo de $27,8 \%$ no município de Palotina ${ }^{5}$. Esta porcentagem mais elevada torna a situação de Palotina de interesse para a análise do fenômeno social proposto, bem como pode contribuir trazendo novos elementos para enriquecer o estudo das relações de gênero e justificando a presente pesquisa.

\section{Método}

Como instrumento de coleta de dados foi utilizada a técnica da entrevista semi-estruturada e para análise das informações o método qualitativo juntamente com o quantitativo.

\section{Sujeitos}

A população desta pesquisa foi formada por 7 adolescentes entre 13 e 18 anos, residentes no Bairro Santa Terezinha, Município de Palotina - Paraná, que tinham em comum o fato de terem engravidado pelo menos uma vez quando solteiras, nos anos de $2000 \mathrm{a}$ 2001 e participavam das reuniões da APMI (Associação de Proteção a Materninada e Infância, 1966) realizadas no bairro ${ }^{6}$.

Quadro 1: Dados Gerais das Adolescentes

\begin{tabular}{|c|c|c|c|c|c|c|}
\hline Nome & Idade & Escolaridade & $\begin{array}{c}\mathbf{N}^{\circ} \text { de } \\
\text { Irmãos }\end{array}$ & $\begin{array}{c}\text { Estado Civil dos } \\
\text { Pais }\end{array}$ & $\begin{array}{c}\text { Renda } \\
\text { Familiar }^{7}\end{array}$ & $\begin{array}{c}\text { Profissão } \\
\text { Exercida }\end{array}$ \\
\hline V.V. & 16 & $\begin{array}{c}8^{\mathrm{a}} \text { série do } \\
1^{\circ} \mathrm{Grau}\end{array}$ & 1 irmã & viúva & 2 a 3 salários & Doméstica \\
\hline R.S. & 16 & $\begin{array}{c}5^{\mathrm{a}} \text { série do } \\
1^{\circ} \mathrm{Grau}\end{array}$ & $\begin{array}{c}1 \text { irmão e } 4 \\
\text { irmãs }\end{array}$ & $\begin{array}{c}\text { moravam juntos e } \\
\text { agora estão }\end{array}$ & 1 a 2 salários & $\begin{array}{c}\text { Sem } \\
\text { especificação }\end{array}$ \\
\hline A.N. & 17 & $\begin{array}{c}2^{\mathrm{a}} \text { série do } \\
2^{\circ} \text { Grau }\end{array}$ & 2 irmãos & casados & 4 a 5 salários & $\begin{array}{c}\text { Loja do Baú, } \\
\text { Central 1,99 e em }\end{array}$ \\
\hline A.P. & 16 & $\begin{array}{c}5^{\mathrm{a}} \text { série do } \\
1^{\circ} \text { Grau }\end{array}$ & $\begin{array}{c}4 \text { irmãos e } \\
4 \text { irmãs }\end{array}$ & $\begin{array}{c}\text { moravam juntos e } \\
\text { agora estão }\end{array}$ & $\begin{array}{c} \pm 2 \text { a } 3 \\
\text { salários }\end{array}$ & Babá \\
\hline G.L. & 18 & $\begin{array}{c}\text { cursando } 3^{\mathrm{a}} \text { série } \\
\text { do } 2^{\circ} \text { Grau }\end{array}$ & 2 irmãos & moram juntos & 4 a 5 salários & babá e doméstica \\
\hline
\end{tabular}

\section{Material}

Foi elaborado para este estudo um questionário dividido em duas partes. A primeira constava de perguntas que tinham o objetivo de conhecer melhor as adolescentes e a segunda abordava questões relacionadas com o tema gravidez na adolescência.
'Conforme dados fornecidos pela Secretaria Municipal de Saúde de Palotina num total de 392 nascidos vivos em 2001, 27,8\% eram filhos de adolescentes entre 10 a 19 anos de idade.

${ }^{6}$ Com a finalidade de preservar a privacidade das adolescentes, as iniciais usadas são fictícias.

7 O salário mínimo da época era de $\mathrm{R} \$ 180,00$. 


\section{Procedimento}

Obtida a concordância das adolescentes em participar da pesquisa, agendava-se a aplicação do questionário num período em que elas estivessem na APMI, tendo-se o cuidado de conversar com elas em particular.

\section{Resultados e Discussão}

Os dados do Quadro 1 mostram que a maioria das famílias das adolescentes é pequena, e a renda geralmente é baixa, com $57 \%$ girando em torno de 1 a 3 salários mínimos, o que significa que as falas analisadas e discutidas neste capítulo refletem o modo de pensar e agir de adolescentes que vivem num contexto social que possui poucos recursos financeiros.

\section{Gravidez na adolescência e mudança no papel social}

Com relação ao papel de estudante e profissional, percebeu-se pelos dados coletados que coexistem num mesmo lugar valores sociais de diferentes períodos, no Brasil. De um lado, adolescentes que possuiam uma visão de mulher que estuda, tem uma profissão e é independente financeiramente. De outro, alguns pais que não permitiam que as filhas trabalhassem fora, pois para eles, exercendo o papel de provedores, era uma questão de honra masculina sustentar a família, principalmente a esposa e filhas.

Relacionando o papel de estudante e profissional feminino com a concepção de maternidade, surgiu uma questão interessante, pois pelas falas, $22 \%$ das adolescentes relaxaram com os cuidados para evitar uma gravidez pelo fato de desejarem ter um filho, demonstrando preocupação com sua fertilidade. Talvez a explicação se deva ao fato do papel de mãe sobressair aos demais favorecendo o florescimento de um desejo inconciente de engravidar.

Outra constatação de mudança pode ser feita comparando o padrão de comportamento que se esperava da mulher no inicio do século passado - ser esposa e mãe - e o que as adolescentes hoje expressam - primeiro estudar, ter uma profissão e depois filhos. Contudo, o que se verifica é que nesse caso ocorre o inverso, pois uma gravidez precoce pospõe o estudo e a profisssão. Diante disto, pergunta-se:
Porque essa inversão? Talvez porque a moral oficial não coincida com os resquícios da cultura masculina, ainda muito fortes, que dão ao papel de mãe a prioridade, deixando-o sobressair aos demais.

Isto parece diretamente relacionado à forma como assuntos ligados a sexo e contracepção são entendidos e tratados por pais e adolescentes, e também à forma como eles próprios vêm o papel sexual. A maioria delas não possui o hábito e a intimidade suficientes que possibilitariam uma conversa franca e aberta com seus pais sobre virgindade, namoro e casamento; $28,6 \%$ não falam nada sobre isto, $28,6 \%$ afirmam que o diálogo é ruim, $14,3 \%$ dizem que é regular e só $28,6 \%$ têm conversas que poderiam ser consideradas boas, mas não ótimas.

$\mathrm{Na}$ fala abaixo encontra-se um exemplo típico que ilustra essa questão:

"É, a minha muiãe não conversava sobre essas coisas. A minha mãe era tipo assim, o meu pai ele só falava: Se você ficar grávida, eu te corto todinha de facão. "Que ele $e$ baiano né! " $E$ u corto você todinha de facão e vou atrás dele!" Ele falava. E, a minha mãe, ela não conversava muito sobre essas coisas. Ela só falava que não podia e só, não explicava porque. (...) Ela só falava que se um dlia eu aparecesse grávida ela me colocava para fora de casa." (G. L.)

Quando perguntada se os pais cumpriram as ameaças ela respondeu:

"O meu pai teve uma reação totalmente diferente. (..) A minha mãe também. Eles só falavam para meter medo. Eu converso com ela agora sobre o porque falava essas coisas. Ela dizia que era pra não fazer, que era um modo que ela me metia medo pra mim não faze, né! Mas eu não achava essa a maneira mais certa, a gente tinha que conversar, explicar o porque do que estava acontecendo... não, nunca falavam nada." (G.L.) 
"(...) Eu nunca tive assim... muito diálogo com os meus pais sobre esse tipo de assunto assim! Só na escola, os meus amigos, as minhas tias eu conversava muito com as irmãs da minha mãe né! Mas com a minha mãe mesmo não!" (...). (G.L.)

A falta de diálogo foi reforçada quando se procurou identificar qual era a opinião dos pais sobre o uso de métodos anticoncepcionais antes do casamento; verificou-se que havia quem os desaprove totalmente, quer dizer, deixavam claro para as filhas que proibiam o intercurso sexual antes do casamento e conseqüentemente também o uso de métodos contraceptivos. Mas, é maior (o dobro) o número daqueles que aprovavam parcialmente, o que significa que não deixavam clara sua posição diante das filhas, porque não recomendavam o intercurso sexual antes dó casamento e o uso de métodos anticoncepcionais, que seriam a prova da ocorrência do relacionamento sexual, e, ao mesmo tempo, não negavam o uso de pílula ou camisinha caso a filha tivesse iniciado a atividade sexual com o namorado. Somente uma mãe apoiava totalmente o uso de algum método para evitar a gravidez não programada de sua filha adolescente.

Importante salientar que desde os anos 50 se vem falando em melhorar o diálogo com os filhos sobre assuntos ligados a sexo e que a escola deveria orientar melhor os adolescentes, só que, como se viu, apesar das transformações permaneceu um quadro cultural de inibição com relação à palavra sexo que impede um diálogo franco sobre virgindade, namoro e casamento, o que faz com que pais e educadores deixem lacunas no preparo dos jovens para o exercício de seu papel sexual, que se encontra em fase de assimilação, nesta etapa, acentuando consequentemente as dúvidas, o que ajuda para que ocorra a gravidez na adolescência.

\section{Perda da Virgindade e suas Implicações com os Conceitos de Namorar/Ficar e Ser Fácil/Ser Dificil}

Conforme a fala das adolescentes o namoro é um compromisso assumido de comum acordo entre as duas partes envolvidas, é um período de tempo em que o casal procura se conhecer melhor para que, tenha condições de decidir se ficarão juntos a fim de formarem uma família. $O$ namoro tem por base o amor, sentimento que justifica a exclusividade e fidelidade entre um homem e uma mulher, que os une, que explica o fato de desejarem ficar juntos e mais tarde constituir um lar com filhos que serão o fruto desse amor.

Há sei lá. O que significa namorar!? Namoro realmente, na minha opinião, quando ele acontece, no meu caso, foi porque eu conheci ele, há muito tempo, a gente ficava, só que a gente nunca namorava, porque eu me achava muito nova, eu não gostava dele o suficiente pra namorar, eu não amava ele, depois que eu descobri que amava, eu procurei ele, conversei, a gente começou a namorar. Então pra mim, sei lá, o que significa, namoro é quando duas pessoas se amam, querem assim ficar junto, sei lá, casar. $O$ casamento começa através do namoro então... Ninguém casa assim, tem que namorar antes, então... namoro é à base do casamento. (A.L.)

Segundo o relato da adolescente, antes de namorar o casal "ficou" várias vezes, mas ela se achava nova é nem tinha certeza de seus sentimentos por ele. Após concluir que amava o seu parceiro, decidiu namorar com ele. Portanto, antes de assumir um compromisso mais sério é preciso ter certeza dos sentimentos que o casal nutre um para com o outro. Observa-se, então, que o "ficar" parece ser o caminho que leva à "namoro", que, por sua vez, pode conduzir ao "casamento", portanto namorar significa mais responsabilidade, e pensar em casar, ter filhos e garantir o seu próprio sustento. Nesse sentido, a adolescência como uma fase de transição, ainda com mais liberdade se encontra presente na fala das adolescentes.

Entretanto, há relatos que parecem trazer uma concepção de namoro parecida com a dos anos 50, mostrando que houve transformações nas concepções, mas que num mesmo espaço geográfico podem conviver idéias diferentes sobre um mesmo tema. 
Há! Namoro é muito bom né, mas só que... só que esses namoro de hoje em dia já vai de transa! Essas coisas, então isso pra mim não é namoro. Namoro assim né. Namoro é namorar e depois casar e depois que vai fazer esse tipo de coisa lfalou bem baixinho], mas hoje em dia não tem isso não! Hoje já faz antes do tempo né. (R.S)

Esta fala permite levantar a questão da prática sexual antes do casamento. Para ela, no namoro, não seria bom ter relações sexuais, mas, nos dias atuais, as pressões sobre as meninas parecem ser de outra natureza, com os rapazes insistindo para que elas se entreguem. Isto põe em evidência a dualidade da sociedade que, por um lado, proclama a liberdade sexual das mulheres, mas não aprova que elas comecem a ter relações quando muito novas e com vários parceiros.

Dando seqüência à discussão, é importante verificar a comparação entre a concepção de "ficar" e a de "namorar", que as adolescentes fazem.

Passa tempo. Tá passando o tempo não tá querendo nada sério (silêncio). (G.L)

Ficar se fica ali uma noite ou duas, pra você tanto faz né! Agora namorar não! Namorar tem aquele negócio de sentimento e coisa e tal, dai já vira bagunça! (V.V.)

Entende-se que 'ficar' é o primeiro contato que as adolescentes fazem com os rapazes. Não é um compromisso sério, pode acontecer numa noite com um determinado rapaz e depois não mais vê-lo. Ficar várias vezes com uma mesma pessoa, indicaria que entre os dois começa a existir um sentimento que os atrai e que pode terminar em namoro. No ficar o casal se abraça, beija e troca carícias chegando ou não a ter intercurso sexual, ou seja, isto não é obrigatório ao primeiro contato com a outra pessoa.

Para entender melhor a interferência da concepção de "ficar" e "namorar" no índice de gravidez não programada na adolescência é necessário apreender também o que significa a virgindade para as adolescentes e o que consideram serem garotas "fáceis" ou "mais dificeis". Moças fáceis são adolescentes que fazem uso de sua liberdade tendo relação com vários parceiros sem compromisso amoroso, procurando encontrar satisfação sexual, utilizando ou não algum método anticoncepcional.

Moças difíceis são as que não têm relações sexuais com facilidade, a menos que sejam seduzidas. Primeiramente, o rapaz deverá conquistar seu coração, convencê-la de que gosta dela e que pretende assumir um compromisso mais sério, para depois, através de carícias fisicas que vão se tornado cada vez mais intensas e íntimas, seduzir a adolescente para que esta mantenha intercurso sexual com ele.

Como se pode verificar, os termos moças mais dificeis ou fáceis estão diretamente ligados com a presença/permissão ou não da relação sexual.

Ao serem indagadas sobre sua opinião com relação ao namoro, se a menina deveria ser "dificil" ou "fácil" de ser conquistada pelos meninos, as adolescentes responderam:

Há! Eu acho assim... que ela não deve ceder pra qualquer um, então eu acho que ela tem que ser um pouco dificil, porque hoje em dia não é fácil encontrar um rapaz bom! Que não bebe, não fuma, que trabalha, que um dia pensa em ter uma família e dessa família... assim... ser mais... ter mais cabeça. Então, eu acho que ela tem que ser um pouco mais dificil. (J.S.)

Essas falas levantam a questão da valorização das adolescentes. Para que a moça consiga um rapaz que queira assumir um compromisso mais sério, que possa terminar na união definitiva do casal através do casamento, por exemplo, ela deve ser mais difícil.

Eu acho que tem que ser um pouco mais difícil. Porque, no namoro, você tá conhecendo a pessoa $e$ você não conhece ela direito, você não sabe se amanhã ela vai estar com você. $E$, que nem no caso... se a menina for virgem, eu acho que ela... a primeira vez da gente é muito importante, pra qualquer um assim... Há! To namorando vou me entregar e pronto. Tem que ser uma coisa especial. Eu acho que a menina 
deveria se valorizar mais, porque hoje em dia só em tá ficando com um cara já tem relação com ele, na primeira vez que tá ficando. A mulher acaba perdendo o seu valor. Devia ser um pouquinho mais difícil... não dar muito mole não. (G.L.)

Segundo a adolescente é preciso primeiro conhecer o menino, gostar dele, namorar, para então poder se entregar mantendo relações sexuais.

Conforme os relatos percebe-se que no 'ficar' não é aconselhável ter relações sexuais, porém, depois de certo tempo de namoro, a entrega amorosa é permitida, o que parece significar mais segurança para a menina de que o pai assuma a criança caso engravide, já que os dois possuem um laço de sentimentos mais forte e exclusividade no relacionamento sexual, o que também evita dúvidas sobre quem seria o verdadeiro pai da criança.

Interessante observar que a maioria das adoelscentes (86\%) engravidou do primeiro parceiro, e somente $14 \%$ disse ter acontecido após o terceiro. $O$ fato de grande parte das meninas ter afirmado que foi com o primeiro namorado que perderem a virgindade, tendo com ele um relacionamento mais sério, mostra a permanência da exigência de inocência das adolescentes, e sua preocupação em serem consideradas mais dificeis, vistas como moralmente mais puras, perante os homens e a sociedade em geral.

Também se obteve como dado que a tendência desse grupo de adolescentes foi perder a virgindade após certo tempo de namoro, variando de 7 meses a 3 anos.

Os dados mostram ainda que $42 \%$ das adolescentes engravidaram antes de completarem um ano depois da perda de sua virgindade, $30 \%$ após um ano de iniciação sexual e uma minoria $14 \%$ depois de 3 anos. Devido ao curto período de tempo entre a perda da virgindade e a ocorrência da gravidez não programada, pode-se afirmar que as meninas não utilizaram corretamente os métodos anticoncepcionais, o que faz retomar a pergunta sobre quais seriam as causas desse fato.

Conforme os dados obtidos a maioria, representando $42 \%$ das adolescentes, juntou-se com seus parceiros, $29 \%$ permaneceu solteira e $29 \%^{8}$ casou no civil. A constatação de que $71 \%^{9}$ dos namoros resultou na união do casal após a ocorrência da gravidez, reforça a questão de que a adolescente ser mais dificil traz segurança para ela caso engravide.

Através dos dados coletados, constata-se que a maioria dos parceiros, $71 \%$, assumiu o filho. Essa porcentagem pode ser explicada pelo dado anterior, que diz ser também mais frequente a adolescente perder a virigindade com o namorado (com exceção de uma) e não com o parceiro ficante. Os $29 \%$ dos rapazes que não assumiram o filho, terminaram o seu relacionamento com a adolescente que permaneceu solteira, diferentemente das demais.

Esses dados reforçam a questão de que a perda da virgindade, quando ocorre após certo período de tempo, atribui à adolescente pureza moral por ter sido mais dificil, pois o relacionamento sexual foi o resultado de uma entrega por amor, depois de o casal ter assumido um compromisso mais sério. Nesse caso, a gravidez não programada de certa maneira é perdoada, pois a adolescente foi levada pelo sentimento e seduzida pelo namorado.

Quando as adolescentes foram questionadas sobre a opinião dos meninos e meninas com os quais conviviam a respeito de virgindade $e$ as moças serem mais fáceis ou mais dificeis, a maioria delas confirma a perda de importância da virgindade, mas também dizem que se a garota é "dificil" ela é mais valorizada.

Como se pode, então, constatar, ao contrário dos anos 50, em que a virgindade era um valor insubstituível, nos tempos atuais, para os homens, o fato de a menina não ser virgem não a desmoraliza. Mas, se ela for uma garota fácil, que permite intimidades fisicas e mantém relações sexuais com vários parceiros, ela perde sua moral, deixando de ser considerada pura e inocente.

As falas analisadas permitem comparar as adolescentes difíceis e fáceis com as moças consideradas levianas e as de família dos anos 50. A que é muito fácil os homens não valorizam, mas as dificeís, as mais comportadas, essas são vistas com bons olhos pelos meninos. Na hora de escolher alguém para namorar sério eles preferem as dificeis.

Reforça-se a dualidade da liberdade sexual

\footnotetext{
* Essa porcentagem corresponde aos $14,3 \%$ que já haviam casado e $14,3 \%$ que estavam com a data do casamento marcada conforme dados do quadro 3.

${ }^{9}$ Os $71 \%$ correspondem aos $42 \%$ das adolescentes que se juntaram, mais os $29 \%$ que casou no civil.
} 
feminina: a mulher pode ter relações com vários parceiros, mas há resquícios de tempos mais antigos que permaneceram, condenando-a se se toprna promíscua.

Ao mesmo tempo em que a moça deve ser sensual e bonita, quando consegue seduzir um homem, é preciso rejeitá-lo e resistir aos avanços e carícias de seu parceiro.

Todas essas idéias são reforçadas pelos dados do comportamento das adolescentes com relação ao uso de preservativos, pois se estabeleceu uma relação entre utilizar camisinha e a moça ser vistas como fácil. Justifica-se a inibição em levar camisinha na bolsa ou chegar a pedir que o menino use; é dentro desta dualidade que se observa o favorecimento da gravidez não programada.

Através das falas também se percebe que cabe à adolescente controlar os seus impulsos sexuais, pois se ela estiver com um rapaz e lhe conceder muitas intimidades, na hora o menino vai gostar, mas depois fará fofocas com os amigos dizendo que ela é muito fácil e que não serve para um compromisso mais sério.

Os dados desse estudo subsidiam, pois, a afirmação de que o índice de gravidez na adolescência, que desperta preocupação, possui relação com as mudanças no papel social desempenhado pelas mulheres, principalmente após a urbanização e a industrialização.

A pergunta que se coloca é: Como essas mudanças no papel desempenhado pelas mulheres poderiam influenciar no índice de gravidez não programada na adolesscência?

Após a consulta à bibliografia e a análise e discussão dos dados coletados junto às adolescentes do Bairro Santa Terezinha de Palotina, chega-se a três conclusões: a) as alterações no papel social das mulheres são históricas, mudam de um lugar para outro, por isso, em contextos diversos são diferentes o modo de pensar o papel de esposa, mãe, o sexual, o profissional e o de estudante que se encontram ligados aos conceitos de virgindade, namoro, maternidade $\mathrm{e}$ casamento; b) apesar das modificações, num mesmo lugar podem conviver diferentes opiniões sobre determindo papel; c) juntamente com as mudanças havidas, permaneceram resquícios dos valores anteriores.
O papel social está ligado à noção de gênero que se refere às relações que existem entre os homens $e$ as mulheres na sociedade, relações que foram sendo construídas com o passar dos anos, que constantemente passam por modificações e se manifestam de maneiras diferentes (Studart, 1991, p. 31$)^{10}$ conforme a época e o lugar.

A industrialização e a urbanização contribuíram para que as concepções de, virgindade, namoro, casamento e maternidade se alterassem, porém, cada contexto social adequa essas mudanças a sua realidade, podendo acontecer de coexistirem num mesmo local diferentes concepções sobre a representação de um determinado papel social, revelando que não existe um consenso geral sobre o papel de esposa, o de mãe, o sexual, o profissional e o de estudante desempenhado pelas mulheres.

Assim, coloca-se como pontos importantes:

a) Permanência de resquícios em torno do conversar sobre sexo, gerando um quadro de inibição cultural que dificulta o diálogo entre pais e filhos sobre virgindade, namoro, relações sexuais e uso de anticoncepcionais, fazendo com que as adolescentes juntem informações através de conversas com amigos, tias, colegas de escola e outras fontes, que nem sempre são completas ou adequadas, favorecendo a ocorrência da gravidez não programada na adolescência.

b) Permanência de resquícios com relação ao papel de mãe e esposa, fazendo com que sejam considerados mais importantes do que o papel profissional da mulher, o que favoreceria também uma gravidez precoce, pois cria um desejo inconsciente de engravidar, fazendo com que as adolescentes não usem adequadamente os métodos anticoncepcionais a fim de verificar a sua fertilidade.

c) Permanência de resquícios em torno da pureza moral, antes atribuída a virgindade, e hoje, ligada ao fato de a adolescente possuir um número reduzido de parceiros e da entrega física ser por amor e não racional, levando à não utilização

\footnotetext{
10 "No fim da década de 60 , anunciavam uma revolução sexual para as mulheres. Nas patotas de Ipanema, bairro da zona sul do Rio, moças perguntavam: 'quem quer transar comigo?' Mas, no interior do Nordeste e de Minas, pais continuavam expulsando de casa as filhas que deixavam de ser virgens e, na maior parte do país, honra e sexo se misturavam."
} 
adequada dos métodos anticoncepcionais.

d) Permanência da atribuição ao homem do papel de conquistador e à mulher o de controle de seus desejos físicos para ser considerada pura, entregando-se somente quando não consegue mais resistir aos avanços do parceiro, que faz com que a adolescente seja envolvida por uma inibição cultural que a impede de pedir que o namorado use camisinha, favorecendo a ocorrência da gravidez.

Como se pode perceber, são os fatores mencionados que levam a colocar que a gravidez não programada na adolescência possui relação com as mudanças pelas quais passou o papel social desempenhado pelas mulheres, mesmo assumindo que essas alterações são históricas e que num mesmo contexto social podem coexistir diferentes opiniões sobre o papel atribuído às mulheres.

\section{Referências Bibliográficas}

Ata de fundação da APMI de Palotina realizada no dia 11 set. 1966. Livro 1, p. 1 frente.

Bassanezi, C. (1997). Mulheres dos anos dourados. p. 607-639. In: M. Del Priore (org.); C. Bassanezi (coord. de textos). História das mulheres no Brasil. São Paulo: Contexto.

D'Incao, M.A (1997). Mulher e família burguesa. p. 223-240. In: M. Del Priore (org.); C. Bassanezi (coord. de textos). História das mulheres no Brasil. São Paulo: Contexto.

DA AE Notícias (2000). Adolescentes têm 22,\% dos partos. Jornal do Oeste, Toledo, n. 4.295, p. 10 , a. 16,8 out.

Desser. N.A. (1993). Adolescência: sexualidade $e$ culpa. Rio de Janeiro: Rosa dos Tempos.

Fonseca, C. (1997). Ser mulher, mãe e pobre. p. 510553. In: M. Del Priore (org.); C. Bassanezi (coord. de textos). História das mulheres no Brasil. São Paulo: Contexto.

Rago, M. (1997). Trabalho feminino e sexualidade. p. 578-606. In: M. Del Priore (org.); C. Bassanezi (coord. de textos). História das mulheres no Brasil. São Paulo: Contexto.
Rodrigues, A. (1992). Relações amorosas: uma incursão sociológica no processo amoroso. Dissertação de Mestrado, Universidade de Brasília, Brasília, DF.

Rosemberg, F. (1994). A educação de mulheres jovens e adultas no Brasil. p. 27-62. In: H.I.B. Saffioti I. B. \& M. Munoz-Vargas(Orgs.). Mulher basileira é assim. Rio de Janeiro: Rosa dos Tempos.

Saffioti, H.I.B. (1994). Introdução. p. 11-26. In: H.I.B. Saffioti \& M. Munoz-Vargas(Orgs.). Mulher basileira é assim. Rio de Janeiro: Rosa dos Tempos.

Studart, H. (1991). Mulher, a quem pertence teu corpo? Uma reflexão sobre a sexualidade feminina. 2. ed. Petrópolis: Vozes.

Observação: Esta pesquisa fez parte de um trabalho acadêmico requisito de avaliação para obtenção do Título de "Bacharel em Ciências Sociais" do Curso de Ciências Sociais, da Faculdade Estadual do Oeste do Paraná Unioeste, tendo-se elaborado um instrumento especialmente para a coleta de dados do estudo. 